\title{
REFLEXÕES SOBRE OS PRESSUPOSTOS DIALÉTICOS DOS DIREITOS SOCIAIS
}

\section{REFLECTIONS ON DIALECTICAL ASSUMPTIONS OF SOCIAL RIGHTS}

\author{
Rosendo Freitas de Amorim ${ }^{1}$ \\ Mylena Maria Silva Reginaldo Ferreira Gomes ${ }^{2}$
}

\section{RESUMO}

O objetivo central deste artigo consiste em traçar um panorama acerca da atualidade do pensamento marxista e de sua pertinência na consolidação de muitos direitos sociais que ocorreram no decorrer dos dois últimos séculos. Com efeito, a contribuição do pensamento de Marx não diz respeito apenas a seara da Economia Política, mas também da Filosofia Política e da Sociologia. Cabe ainda enfatizarmos que o pensamento marxista não se manteve uniforme durante o seu desenvolvimento, tendo de início adotado uma concepção mais próxima da filosofia hegeliana e posteriormente rompido com esta forma de interpretação a partir do materialismo histórico e dialético. Por isso, é fundamental iniciar-se uma análise de Marx a partir de seus escritos juvenis, quando aborda a questão da alienação e posteriormente da contribuição que teve o Manifesto do Partido Comunista na difusão de seu pensamento. Posteriormente, o trabalho passa a analisar a contribuição do pensamento marxista dentro da política de efetivação dos direitos sociais, como suas ideias foram relevantes para que pós 1917 uma série de direitos sociais fossem previstos constitucionalmente. Por fim, aborda-se a atualidade do pensamento marxista e em que contexto deve ser repensado.

Palavras-chave: Marxismo. Dialética. Manifesto do Partido Comunista. Direitos Sociais.

\begin{abstract}
The central aim of this article is to outline the current relevance of Marxist thought and its relevance to the consolidation of many social rights that have occurred over the last two centuries. In fact, the contribution of Marx's thought concerns not only the field of Political Economy, but also of Political Philosophy and Sociology. It is important to emphasize that Marxist thought did not remain uniform during its development, having at first adopted a conception closer to Hegelian philosophy and later broken with this form of interpretation from historical and dialectical materialism. For this reason, it is fundamental to begin an analysis of Marx from his juvenile writings, when he approaches the question of alienation and later the contribution that the Manifesto of the Communist Party had in the diffusion of his thought. Subsequently, the work begins to analyze the contribution of Marxist thought within the policy of effective social rights, as their ideas were relevant so that after 1917 a series of social rights

\footnotetext{
${ }^{1}$ Professor Titular do Programa de Pós-Graduação em Direito Constitucional da Universidade de Fortaleza (UNIFOR). Universidade de Fortaleza (UNIFOR) - Brasil. Lattes: http://lattes.cnpq.br/5788651334387181 ORCID: http://orcid.org/0000-0003-1498-8999 E-mail: rosendo@unifor.br

${ }^{2}$ Mestranda em Direito Constitucional pela Universidade de Fortaleza (UNIFOR). Universidade de Fortaleza (UNIFOR) - Brasil. E-mail: mylenamagomes@edu.unifor.br
} 
were constitutionally foreseen. Finally, we discuss the actuality of Marxist thought and in what context it must be rethought.

KEY WORDS: Marxism. Dialectic. Manifest of the Communist Party. Social rights.

\section{INTRODUÇÃO}

O artigo em referência se propõe a fazer uma análise da importância do pensamento marxista para a consolidação e efetivação de muitos direitos sociais pós 1917. A data é paradigmática, pois tanto foi o ano que se desencadeou a Revolução Russa, quanto foi o ano de promulgação da Constituição do México. A primeira representou uma tentativa de revolução da classe dominada e a segunda foi o primeiro texto constitucional a prever uma série de direitos sociais antes excluídos do papel Estatal. Estes dois marcos tiveram como fundamento o pensamento marxista que se desenvolveu no século XIX, a partir da análise feita pela sociedade, durante a Revolução Industrial, por Karl Marx, com as contribuições de Friedrich Engels.

A primeira seção aborda os escritos de juventude de Karl Marx e sua importância para a consolidação de seu pensamento, pois sua base filosófica foi relevante para a compreensão do que se entende por Estado, sociedade civil e interesses sociais. Neste período, havia uma estreita ligação com a filosofia hegeliana que posteriormente Marx concluiu que não se prestava para promover uma ruptura com o status quo, pois esta filosofia não promovia uma verdadeira reflexão sobre distinção que deveria haver entre o Estado e a sociedade e que esta não era produto daquele. Assim, Marx conclui que somente a partir da dialética é possível promover uma mudança das relações sociais, a ponto de inverter a ordem existente.

A sessão seguinte aborda mais detidamente a importância do materialismo histórico e dialético, a partir da dialética se analisa as transformações sociais verificadas no desencadeamento da Revolução Industrial e como foi necessária a consciência deste processo para que uma efetiva mudança fosse operada. Esta mudança deveria operar-se a partir do momento em que a classe dominada promovesse uma revolução.

Posteriormente, na terceira sessão passa-se a abordar a importância que teve o Manifesto do Partido Comunista (1848) na difusão do pensamento marxista no Ocidente. Neste escrito, Marx e Engels abordaram de forma lapidar o problema da luta de classes e que se tratava um fato que recorrente nas sociedades. A luta de classes é o tema central do manifesto, mas além 
deste aborda também a questão das desigualdades verificadas com o desenvolvimento do capitalismo, como a ausência de distribuição da riqueza gerada pelo trabalho e o aumento da miséria. A obra incita a classe proletária a manter-se unida como forma de promover uma revolução e modificar esta ordem existente.

Na quarta sessão passa-se a examinar as modificações desencadeadas pós 1917, quando se operaram a Revolução Russa e o advento da Constituição mexicana, marcos históricos na tentativa de concretização da necessidade de se repensar o Estado, a partir do pensamento marxista. Com o advento de direitos sociais para o plano estatal como forma de mitigar os efeitos deletérios do desenvolvimento do capitalismo.

Por fim, a quinta sessão aborda a atualidade do pensamento marxista, defendida por muitos como não mais aplicável a contemporaneidade, pois não houve o fim do capitalismo, bem como pela não concretização do comunismo. Contudo, muito embora não tenha se verificado o fim do capitalismo e a instituição do regime comunista não se deve rechaçar a importância do pensamento marxista, mormente se analisarmos o advento de muitas crises geradas pelo capitalismo que redundaram numa diminuição do tamanho do Estado, hoje Estado Regulador; e pelo aumento da sociedade de consumo, uma nova forma de alienação verificada.

Trata-se de uma pesquisa qualitativa, de natureza teórica fundamentada em referencial bibliográfico pertinente à temática.

\section{OS ESCRITOS DO JOVEM MARX}

\subsection{A Filosofia política de Marx}

Da análise do pensamento de Karl Heinrich Marx e de sua contribuição para as ciências humanas, tanto sob o ponto de vista sociológico, filosófico e econômico, é mister ressaltar que sua obra não se manteve uniforme durante os anos de sua produção intelectual. Com efeito, é fato que o pensamento de Marx pode ser dividido em duas vertentes: a primeira ${ }^{1}$, que é conhecida como período de produção da juventude, em que existia um acentuado caráter filosófico, e portanto, influenciada pela filosofia idealista de Georg Wilhelm Friedrich Hegel; e

\footnotetext{
1. Nesse primeiro momento não existe um entendimento uniforme entre seus estudiosos acerca do início e fim dos escritos de juventude de Marx. Ao analisar a obra de Norberto Bobbio, verbi gratia, este enfatiza que as obras de juventude de Marx vão dos anos de 1838 a 1845, período em que estudou em Berlim, tendo participado do movimento dos jovens hegelianos (Bobbio, p. 106, 2018). Já ao se analisar a obra de Raymund Aron, outro estudioso da obra do pensador, verifica-se que a data de produção das obras consideradas de juventude variam entre os anos de 1844 a 1847. (ARON, p. 25, 2005).
} 
uma segunda fase, conhecida como fase de maturidade, que é caracterizada por uma ruptura com o pensamento hegeliano, sua construção intelectual transmuda-se da filosofia política para a economia política, neste último período efetivamente se desenvolveu o pensamento marxista.

Este primeiro período de seus trabalhos, de acentuado caráter filosófico, muito embora também tenha escrito sobre outros temas que não filosóficos, é marcado por forte influência da filosofia clássica, que tem como um dos maiores expoentes Hegel. A tradição filosófica dominante na Europa dos séculos XIX e XX, pressupunha a existência, além do mundo sensível e histórico, de um mundo caracterizado pela existência de substâncias imutáveis que seriam os verdadeiros objetos do conhecimento (QUINTANEIRO, p. 28, 2009). Assim, gradualmente, os caminhos da razão e a história irão se aproximando.

Faz-se necessário salientar que a análise do conjunto da obra de juventude de Marx somente passou a ser de acesso aos estudiosos, principalmente a partir de 1932, quando dois de seus escritos foram publicados integralmente, no caso as obras A ideologia alemã e Manuscritos econômicos filosóficos ${ }^{2}$. Ao analisar sua produção intelectual, durante esta fase, verifica-se que a obra de Marx tece críticas ao Estado, à política e ao direito, em verdade Marx rebela-se contra a filosofia hegeliana em que o Estado era a esfera do altruísmo universal e em seu âmbito é que se realizavam os interesses da sociedade civil (BORON, p. 296, 2006). Marx mostra que o Estado, enquanto estrutura oficial, presta-se a mantença de um status quo, de uma classe dominante, que muitas vezes se vale da religião e outras formas de dominação para sua mantença.

Nestes termos, interessante citarmos a conclusão de Popper ao analisar a filosofia hegeliana sobre o Estado:

Sua doutrina é a de que o Estado é tudo e, o indivíduo, nada, pois deve tudo ao Estado, tanto sua existência física como espiritual. Esta é a mensagem de Platão, do prussianismo de Frederico Guilherme e de Hegel. "O universal se encontra no Estado", escreve Hegel. "O Estado é a Ideia Divina tal como existe na terra...Devemos, portanto, adorar o Estado como manifestação do Divino sobre a terra, e considerar que, se é difícil compreender a natureza, infinitamente mais árduo será apreender a essência do Estado...O Estado é a marcha de Deus pelo mundo...O Estado deve ser compreendido como um organismo...Ao Estado completo pertencem, essencialmente, a consciência e o pensamento. O Estado sabe o que quer...O Estado é real; e a verdadeira realidade é necessária. O que é real é eternamente necessário...O Estado existe...em razão de si mesmo. O Estado é o que efetivamente existe, a vida moral realizada.” (p. 28, 1987)

\footnotetext{
${ }^{2}$ De salientar que esses mesmos textos já eram de conhecimento dos estudiosos, contudo, apenas parte das obras. As publicações integrais de seu teor, somente ocorreram postumamente em 1932. (ARON, p. 25, 2005)
} 
Ou seja, esta ideia de Estado concebida por Hegel não existe, e é refutada por Marx que conclui que o ente estatal está à disposição das superestruturas ${ }^{3}$ para a manutenção dos interesses das classes dominantes. A partir destas conclusões Marx abandona sua filosofia política e aproxima-se da economia política como forma de provar que o Estado posto não se preocupa com um a igualdade material e que o desenvolvimento do capitalismo aumenta o fosso das desigualdades sociais. A ordem inverteu-se a tal ponto que a política passou a estar à disposição da economia como forma neutralizar toda e qualquer forma de desenvolvimento das condições materiais que tentassem inverter este processo de dominação da economia.

Outro ponto que merece destaque é a leitura feita por Marx ao conceito de sociedade civil existente em Hegel. Com efeito, este restabelece a distinção entre Estado e sociedade civil formulada no século XVIII pelos pensadores, colocando o Estado como fundamento da sociedade civil e da família, e não o revés. Assim, no pensamento hegeliano não existe sociedade civil sem que o Estado a construa, pois é o Estado que funda o povo e não o contrário (GRUPPI, p. 24, 1996). Trata-se, portanto, de uma concepção contrária ao pensamento de Rousseau de que a soberania é do povo. Em verdade a soberania pertence ao Estado, portanto, infere-se que para Hegel a sociedade civil é incorporada ao Estado e que se aniquila neste. Marx também rebelou-se contra esta concepção hegeliana da sociedade civil. Assim, não é o Estado quem funda a sociedade civil, em verdade é a sociedade civil, que explica o surgimento do Estado, seu caráter, a natureza de suas leis e sua ideologia. Partindo-se destas premissas, em sua obra $A$ ideologia alema $\tilde{a}^{4}$, Marx elaborou a essência de seu método ao descobrir a correlação existente entre o desenvolvimento das relações econômicas, o Estado e a ideologia. Verificouse que os aparatos estatais estão à disposição da classe dominante, no caso a econômica, para a mantença do status quo ${ }^{5}$.

\subsection{A dialética hegeliana e o problema da alienação}

De igual relevância dentro de compreensão dos escritos de Marx na juventude é o

\footnotetext{
${ }^{3}$ Por oportuno, cabe frisarmos que Marx concebe a existência de infraestruturas, que seriam as forças produtivas e as relações sociais de redução; e das superestruturas que seriam as relações ideológicas, políticas e jurídicas. (FREITAS, p. 647, 2013).

${ }^{4}$ Esta obra somente foi publicada integralmente em 1932, juntamente a obra Manuscritos econômicos filosóficos (ARON, p. 25, 2005).

${ }^{5}$ Consoante tão bem ressaltou Gruppi: "na verdade a sociedade civil, isto é, as relações econômicas, vivem no quadro de um Estado determinado, na medida que o Estado garante aquelas relações econômicas". E conclui de forma lapidar: "pode-se dizer que o Estado é parte essencial da estrutura econômica, é um elemento essencial da estrutura econômica, justamente porque a garante". (p. 27, 1996).
} 
entendimento da dialética hegeliana. Por oportuno, cabe registrarmos que a noção de dialética remonta do pensamento clássico grego.

Dialética era, na Grécia antiga, a arte do diálogo. Aos poucos passou a ser a arte de, no diálogo, demonstrar uma tese por meio de uma argumentação capaz de definir e distinguir claramente os conceitos envolvidos na discussão. (KONDER, p. 08, 2008). No decorrer dos séculos, o conceito a e importância da dialética foram modificadas e postas em cheque, pois dependendo do tipo de sociedade sua relevância era maior ou menor ${ }^{6}$. No entanto, deve-se ressaltar que uma das características essenciais da dialética é o espírito crítico e a constante reinterpretação que os conceitos podem sofrer. Na singela observação de Marx "Duvidar de tudo".

O estudo e compreensão da dialética teve significativa contribuição de Hegel, em sua obra A ciência da lógica, que concordando em parte com o pensamento de Kant fez considerações importantes acerca da dialética. Segundo Hegel o homem transforma ativamente a realidade que o circunda, mas quem impõe o ritmo dessas mudanças é a realidade objetiva. Uma dessas condições objetivas seria o trabalho, que opera diretamente no desenvolvimento humano. Durante este período Hegel observou que as revoluções francesas e inglesas estavam se operando, em grande medida, a partir das transformações verificadas pelo trabalho, mais especificamente das condições do trabalho. É a partir do trabalho que muitas das habilidades são desenvolvidas, como a superação e a resistência. Ou seja, a partir do trabalho o homem desloca-se de sua condição natural e com isto se emancipa de sua condição estritamente animal. A dialética hegeliana teve papel fundamental no desenvolvimento da filosofia clássica ${ }^{7}$.

Marx observou que de fato o trabalho era a mola propulsora de muitas transformações sociais, contudo, discordava em parte de Hegel, pois não apenas o trabalho intelectual era

\footnotetext{
${ }^{6}$ De salientar que não é objeto deste artigo uma análise detalhada do que venha a ser dialética e suas transformações no decorrer dos séculos. Contudo, algumas notas devem ser feitas para o entendimento da dialética. Segundo Konder (2005, pag. 11-14) durante o período feudal o estudo da dialética foi reduzido e ponto de ser confundido com a metafísica, nesse período o que prevalecia era a ideologia das classes dominantes, sendo monopólio da igreja o acesso aos estudos sobre a dialética. $\mathrm{O}$ estudo da dialética no período feudal era privilégio de uma pequena parcela da população; como se tratava de sociedade bastante estratificada não era de conhecimento de grande parte da população o acesso ao estudo da dialética. Com o advento do Renascimento, a dialética ressurge e passa a ser objeto de estudos da filosofia, não sendo privilégio de uma pequena parcela o seu conhecimento. Outro período fundamental para o desenvolvimento da dialética foi o Iluminismo, a partir do desenvolvimento da razão humana.

${ }^{7}$ É importante ressaltarmos que alguns estudiosos ao se referirem ao pensamento de Hegel destacam a sua peculiar "visão invertida", nestes termos enfatiza Boron: a "visão invertida" de Hegel tinha, tal como dizíamos anteriormente, raízes profundas que se fincavam na estrutura mesma da sociedade burguesa. Se Hegel "via o mundo ao contrário" e fazia com que a dialética andasse de cabeça para baixo, isso não se devia a um problema epistemológico específico, mas sim a que ele reproduzia com fidelidade, em sua construção teórica, a inversão própria do capitalismo. (p. 299, 2006)
} 
responsável por estas transformações, mas de igual modo o trabalho manual. Ora, ignorar o trabalho físico/manual, tal qual Hegel asseverava, acarretava uma compreensão incompleta das transformações acarretadas pelo trabalho, notadamente as de cunho negativo como a alienação ${ }^{8}$ do trabalho nas sociedades divididas em classes. (KONDER, p. 28, 2005).

Marx compreendeu que a dialética hegeliana não se aplicava as condições de trabalho e a propriedade privada verificados durante o século XIX, pois não era capaz de dar respostas as condições de trabalho verificadas durante o desenvolvimento de Revolução Industrial, da desigualdade social verificada pela injusta divisão da riqueza e da propriedade privada geradas pelo capitalismo. Esta injusta distribuição da riqueza devia-se a injusta divisão social do trabalho e da propriedade.

Essas mazelas verificadas por Marx acarretaram um aumento do fosso das desigualdades, pois a expansão do capitalismo necessitava de mais mercados para escoar a sua produção, tornando os trabalhadores comparáveis a mercadorias que produziam. Assim, Marx rompe com a dialética hegeliana, tendo em vista a ausência de respostas para muitas das inquietações verificadas durante sua análise das consequências geradas pela divisão social do trabalho e da propriedade privada. Ou seja, a constatação do caráter materialista da dialética.

Assim, verifica-se que o substrato adquirido por Marx ao estudar a reinterpretar os ensinamentos de Hegel, através da dialética, tiveram papel fundamental no desenvolvimento do pensamento marxista e na construção de sua teoria da economia política. Eis as principais notas acerca dos escritos juvenis de Marx.

\section{O MATERIALISMO HISTÓRICO E DIALÉTICO}

Antes de passarmos a análise do que se entende por materialismo histórico, deve-se salientar no decorrer do século XVIII existiam duas correntes de pensamento filosófico na Europa. Ao desenvolver o método materialista histórico, Karl Marx e Friedrich Engels, rompem com o então pensamento filosófico existentes.

A primeira corrente existente era dita materialista mecânica, pois defendia que as concepções e ideias dos homens eram produtos do meio social em que os homens estavam inseridos. Ou seja, a consciência humana era formada a partir das circunstâncias materiais

\footnotetext{
${ }^{8}$ De salientar que Marx analisou vários tipos de alienação: religiosa, política, filosófica e econômica. (BORON, p. 299, 2006)
} 
(SILVA, p. 02, 2015). De acordo com esta corrente filosófica a ignorância dos homens era desencadeada pela realidade social, pois esta dita realidade era fundamental para o processo de formação das ideologias, ideias e concepções de mundo que o homem passava a introjetar. Assim, segundo esta corrente de pensamento os dogmas, preconceitos, valores e a ignorância tinha origem as circunstâncias materiais. (LOWY, p. 19, 1999).

Para tentar romper com este ciclo de ignorância e mudar a realidade social era necessária a presença de um indivíduo extraordinário, com amplo conhecimento a tal ponto que pudesse mudar esta realidade posta. Os pensadores desta corrente defendiam que este homem excepcional, capaz de mudar a realidade social, poderia ser encontrado em alguns monarcas, sendo estes conhecidos como déspotas esclarecidos ${ }^{9}$. Essa corrente de pensamento desenvolveu-se principalmente durante o período feudal e do absolutismo monárquico, tendo também se estendido pelo século XIX. A crítica que se faz aos materialistas mecânicos é que estes déspotas tinham tanta consciência de seu poderio que pouco fizeram para a mudança desta realidade existente, pois a modificação da realidade existente poderia desencadear a mudança do comando do poder e assim muitos temiam pelo fim de suas hegemonias.

Em oposição a essa forma de materialismo, outra escola do pensamento era conhecida como idealista, sendo representada pelos neo-hegelianos, que acreditavam que para mudar a realidade seria necessário um posicionamento crítico, uma luta contra as formas postas dentro da sociedade. De salientar que esta corrente filosófica não deve ser confundida com o idealismo de Hegel, pois este era de matiz conservadora. Em verdade, se tratava de um idealismo crítico e revolucionário. Isto é, uma luta contra as formas de poder existentes, pois eles acreditavam que criticando as ideias equivocadas, transformando a consciência, a ideologia ou o pensamento dos homens, transformariam a sociedade. A mudança ocorreria a partir da adoção de um posicionamento crítico em relação a ordem existente. Assim, diferentemente dos materialistas que a acreditavam que a realidade influenciava na ordem existente; os idealistas posicionavamse na força do pensamento como forma de modificar a realidade.

Marx a partir da análise crítica das duas correntes de pensamento filosófico existentes chega a conclusão que ambas não apresentam uma justificativa para as condições existentes, pois analisam o problema de forma incompleta. Assim, o materialismo histórico, desenvolvido

\footnotetext{
${ }^{9}$ A propósito os déspotas esclarecidos surgiram durante o período absolutista e podemos citar como exemplos: o Rei Frederico II da Prússia e a Rainha Catarina I da Rússia. De acordo com Löwy esses déspotas teriam a grandiosa tarefa de romper com as circunstâncias e criar novas, que produziriam educação, conhecimentos, e assim, romperiam com a ordem existente.
} 
por Karl Marx e Friedrich Engels, caracteriza-se por adotar uma postura distinta dos métodos acima especificados, trazendo a dialética como forma de compreensão das transformações sociais do mundo ${ }^{10}$. Segundo Quintaneiro: a realidade histórica desenvolve-se enquanto manifestação da razão, num processo incessante de autossuperação desencadeado pelo conflito e pela contradição que lhe são inerentes (p. 28, 2009).

Para o marxismo o que faz operar uma mudança da realidade existente é uma ação revolucionária, capaz de transformar simultaneamente, a sociedade, o Estado, a economia e o próprio indivíduo. Assim, para que se opere esta transformação da realidade existente é preciso que ocorra uma análise do contexto histórico em que estas transformações se operaram.

Ao analisar a importância do materialismo histórico Lukács enfatiza que o materialismo histórico trata-se do método científico capaz de compreender os acontecimentos do passado em sua essência verdadeira e nos permite, ao mesmo tempo, considerar o presente sob o ponto de vista da história e assim possibilitar uma visão mais aprofundada da realidade que nos cerca. Conclui Lukács que o materialismo histórico tinha para o proletariado um valor muito maior do que um método científico de investigação da realidade, pois possibilita uma verdadeira tomada de consciência e mudança da ordem social posta. (p. 415, 2003)

Assim, a função mais nobre do materialismo histórico não podia residir no conhecimento científico puro, as no fato de ser um ato. O materialismo histórico não era um fim em si mesmo, era um meio que permitia ao proletariado esclarecer uma situação e, nessa situação claramente conhecida, agir corretamente de acordo com sua situação de classe. Na época do capitalismo, portanto, o materialismo histórico era um instrumento de luta. (p. 416, 2003)

Portanto, ao desenvolver o método filosófico materialista histórico e dialético, Marx e Engels, rompem com a ordem posta e contribuem para a uma análise mais profundas das transformações sociais pelas quais passava a sociedade, a importância do desenvolvimento da consciência da lutas de classes para que se mudasse a ordem posta.

\section{A IMPORTÂNCIA DO MANIFESTO COMUNISTA DE 1848}

Embora não seja considerado um texto de cunho científico por parte dos estudiosos ${ }^{11}$

\footnotetext{
${ }^{10} \mathrm{O}$ primeiro texto de Marx que enfrenta esta questão e as Teses sobre Feuerbach, escritas em 1845, somente para conhecimento dos estudiosos post mortem, tendo sido publicadas por Engels, que as considerava relevante, pois representavam uma nova concepção de mundo. (LOWY, p. 22, 1999).

${ }^{11}$ Observação feita por Raymund Aron, em O Marxismo de Marx, p. 50.
} 
não se pode refutar a importância que o Manifesto do partido comunista ${ }^{12}$ teve para a divulgação de um dos temas centrais do pensamento marxista: a problemática da luta de classes.

Nesta obra Marx e Engels fazem uma análise das condições em que vivem a sociedade e que pode ser dividida entre a constante luta entre os oprimidos e opressores e que isto sempre esteve presente nas sociedades, ou seja, não se tratava de uma disfunção da contemporaneidade. Estando presente, portanto, em outras sociedades, como na lutas entre o homem livre e seus escravos; ou então do senhor feudal e seus servos; daqueles que detêm os meios de produção e aqueles que possuem a força de trabalho, em suma: opressores e oprimidos estiveram em permanente oposição. Segundo ainda Marx e Engels esta oposição permanece nas sociedades ditas capitalistas:

Nas mais remotas épocas da História, verificamos, quase por toda a parte, uma completa estruturação da sociedade em classes distintas, uma múltipla gradação das posições sociais. Na Roma antiga encontramos patrícios, cavaleiros, plebeus, escravos; na Idade Média, senhores, vassalos, mestres de corporações, aprendizes, companheiros, servos; e, cada uma dessas classes, outras gradações particulares. A sociedade burguesa moderna, que brotou das ruínas da sociedade feudal, não aboliu os antagonismos de classe. Não fez mais do que estabelecer novas classes, novas condições de opressão, novas formas de luta em lugar das que existiam no passado. (MARX, p. 40, 2010)

A propósito cabe aqui fazermos algumas digressões acerca do surgimento do capitalismo. De início, cabe enfatizarmos que o surgimento do capitalismo está atrelado ao surgimento dos primeiros burgos, que eram os centros de trocas existentes no período feudal. Nestes burgos, o desenvolvimento do comércio deu-se a partir das trocas que eram verificadas entre os artesãos, agricultores, corporações de ofício e moradores dos burgos. Neste período, ainda era acentuado o caráter coletivo das sociedades, contudo, com o desenvolvimento dos burgos, que posteriormente formaram as primeiras cidades modernas, o caráter individualista passou a ser a tônica destas cidades. Com efeito, anteriormente, tínhamos uma sociedade em que os interesses coletivos eram relevantes para os membros da sociedade. Assim, em grande medida, as decisões das cidades eram tomadas pelos membros da comunidade. Entretanto, com o desenvolvimento dos burgos e surgimento das primeiras cidades o que se verificou foi que o desenvolvimento do comércio passou a ser atividade principal, consequentemente os interesses

\footnotetext{
${ }^{12}$ O Manifesto do partido comunista foi publicado pela primeira vez em fevereiro ou março de 1848 , tendo sido encomendado no ano anterior pela Liga dos Comunistas, pois se acreditava que a Europa estava às vésperas de uma revolução. Embora a dita revolução não tenha se operado no continente europeu, O Manifesto do partido comunista, é considerado um importante documento político, não ficando restrita a sua relevância apenas aos anos que se sucederam a sua publicação. (LASKI, p. 182, 2010).
} 
coletivos foram deixados de lado.

Ora, estas observações acerca do surgimento da classe burguesa são fundamentais para que se tenha uma análise mais aprofundada do contexto em que se desenvolveu o pensamento marxista, pois este se caracterizou por tentar explicar que o desenvolvimento do capitalismo e consequentemente ascensão da classe burguesa foram responsáveis por aprofundar a miséria e as desigualdades sociais existentes, e portanto a necessidade de que a classe dominada tomasse consciência dessa situação e tentasse modificá-la, através da luta de classes.

Ao elaborarem O Manifesto do Partido Comunista, Marx e Engels apontam as duas contradições verificadas dentro do regime capitalista. A primeira é a contradição entre as forças e as relações de produção. Com efeito, a burguesia cria meios de produção mais poderosos. No entanto, as relações de produção não se transformam no mesmo ritmo. Basta verificar, verbi gratia, com o desenvolvimento dos meios de produção houve uma especialização do trabalho e consequentemente do aumento da produção, contudo, isto não foi acompanhado de um aumento do valor dos salários de seus empregados e tampouco da diminuição das horas de trabalho. A segunda contradição verificada diz respeito ao crescimento da riqueza gerada, contudo, isto foi acompanhado do aumento da miséria da maioria, pois a riqueza ficava concentrada nas mãos de uma minoria. (ARON, P. 51, 2005).

Outro enfoque apresentado no Manifesto, diz respeito ao caráter revolucionário que a burguesia impõe as relações sociais do trabalho, e, por conseguinte, as antigas divisões de produção e de classes existentes foram modificadas com o desenvolvimento do capitalismo. Marx e forma lapidar acentua este caráter revolucionário da burguesia: tudo o que era sólido e estável se desmancha no ar, tudo o que era sagrado é profanado e os homens são finalmente obrigados a encarar sem ilusões a sua posição social e as suas relações com os outros homens (MARX, p. 43, 2010).

Destarte, a única forma de se tentar inverter esta ordem é por intermédio de uma revolução, pois o caráter contraditório do capitalismo em que os detentores do meios de produção ficam cada vez mais ricos, em comparação com os detentores da força do trabalho, cada vez mais se traduz em um duplo processo de proletarização; somente pode ser invertido a partir de um processo de ruptura ofertado por uma revolução. A única classe que poderia impor este caráter revolucionário se contrapondo à classe burguesa seria a classe do proletariado.

Konder enfatiza: 
Os marxistas acham que a única maneira de superar a divisão da sociedade em classes e dá início a um processo de "desalienação" do trabalho é levar em conta a realidade da luta de classes para promover a revolução socialista. Marx não inventou a luta de classes: limitou-se a reconhecer que ela existia e procurou extrair as consequências de sua existência. (...) Marx reexaminou a história social da humanidade e concluiu, em 1848, no Manifesto Comunista, que toda a história transcorrida até então tinha sido uma história de luta de classes. (p. 32-33, 2005).

Assim, muito embora não se trate de um manifesto e que, portanto, despido de cientificidade não se deve desconsiderar a importância que O Manifesto do partido comunista teve para a difusão de um dos temas centrais do pensamento marxista que diz respeito a luta de classes e a importância que se deve atribuir ao proletariado para tentar inverter a ordem existente. A luta revolucionária sempre teve por objetivo o fim da exploração e, portanto, a libertação do homem. (ALTHUSSER, p. 183, 2015).

\section{A INFLUÊNCIA DO PENSAMENTO MARXISTA PÓS 1917}

\subsection{A importância da teoria marxista no desenvolvimento dos direitos sociais}

Muito embora as ideias marxistas não tenham proporcionado o desencadeamento de modificações estruturais quando durante o século XIX, período em que Marx e Engels viveram, é de suma importância que suas ideias foram de fundamentais e desencadearam uma série de mudanças no século passado, notadamente a partir de 1917. É inegável a contribuição do pensamento marxista a partir da leitura dos fenômenos sociais e políticos que tem como marca a luta de classes.

Com efeito, é de se registrar que as origens do constitucionalismo demonstram a contribuição valorosa das revoluções francesa, inglesa e americana na consolidação das Constituições como carta de postulados das principais diretrizes dos Estados. É de se registrar que estas constituições são produtos da revolução liberal burguesa e que, portanto, primavam pela promoção e proteção dos interesses da classe dominante. Marx através da análise das estruturas sociais que se desenvolveram nos séculos XVIII e XIX conclui que tanto o Estado, como a religião e outras superestruturas são utilizadas para fazer valer os interesses desta classe dominante. Ou seja, as ideologias.

Cabe registrar que constitucionalismo moderno de viés liberal, em sua origem, tenta promover a proteção dos interesses da classe dominante. Sendo assim, na pauta dos interesses da classe burguesa estava a promoção dos direitos políticos, como forma de romper com o 
modelo anterior de economia feudal e regime político absolutista em que a burguesia não detinha poderes; da propriedade privada e da liberdade. Ora, a preservação destes direitos era de suma importância a consolidação das ideologias da classe burguesa. A tônica nesta fase do constitucionalismo era a não intervenção do Estado, mesmo que isso gerasse uma omissão do poder estatal em relação a uma série de desigualdades que foram geradas e que o Estado se manteve inerte. Era o que se convencionou chamar de direito de cunho negativo, uma das principais características da teoria política do liberalismo ${ }^{13}$. (ALARCON, p. 555, 2005).

Ora, com a difusão do pensamento marxista, de início de matiz filosófica e posteriormente econômica, tentou-se enfatizar que a concepção e Estado posta não promoveria a igualdade material entre os homens, pois não seria capaz de reduzir o fosso das desigualdades, já que era um modelo concebido a partir da desnecessidade de intervenção do Estado para assegurar que outras classes políticas tivessem acesso ao produto da riqueza gerado pelo capital. Com a difusão das ideias de Marx e Engels, notadamente a conscientização e poder revolucionário do proletariado, que na concepção do pensamento marxista era a única capaz de promover uma revolução capaz de alterar o status quo. De forma lapidar enfatiza Alarcon:

Apesar de posturas divergentes, existem motivos de sobra para dizer que os postulados do materialismo histórico, que constituem o centro da interpretação marxista da história e que partem da diferenciação de setores ou classes sociais em conflito, não podem nem devem ser descartados como elementos de interpretação da realidade contemporânea e, destarte, fatores disciplinadores das mudanças constitucionais. Para além dos méritos da interpretação, o que parece ainda mais interessante é que o pensamento marxista, como observaremos posteriormente, abala a certeza da efetividade de uma constituição jurídica superior à realidade fática. (p. 556, 2005).

Deve-se enfatizar que quando a classe burguesa ascendeu ao poder, a partir da revolução francesa, ocorreu a ruptura das forças de poder, pois anteriormente ao advento da revolução, o que tínhamos era uma França em que o poder estava concentrado na aristocracia e na figura do rei, contudo o terceiro estado não detinha força política, tampouco poder. Essa ascensão burguesa somente se deu em decorrência de uma revolução praticada pela própria burguesia que há época detinha as condições econômicas favoráveis para modificar as forças políticas. De mesma forma, quando nos idos do século XX o proletariado se revolta contra a classe burguesa e impõe reformas constitucionais significativas é porque discorda deste modelo

\footnotetext{
${ }^{13}$ Não é objeto deste artigo a análise do que se entende por liberalismo, no entanto, em linhas gerais pode-se dizer que o liberalismo esteve presente na formulação dos direitos de primeira geração, como a liberdade e a propriedade privada. As constituições modernas são fruto deste pensamento liberal.
} 
burguês em que há um aumento da concentração de renda e não distribuição da riqueza gerada pelo capital. Portanto, cada modificação estrutural nos meios de produção do trabalho desencadeia uma mudança na correlação de forças e surge uma nova classe política dominante.

Com o advento do constitucionalismo liberal burguês inaugurado a partir das revoluções francesas, americana e inglesa constatou-se que Estado era concebido como uma estrutura que deveria assegurar a consolidação da propriedade privada e da liberdade individual em detrimento da efetivação de muitos direitos sociais, pois o que deveria prevalecer eram os interesses da classe burguesa que havia promovido a revolução. Assim, a atuação estatal era no sentido de promover a observância de direitos que culminassem com a efetivação, omitindo-se em relação aos interesses de uma parte da sociedade que não detinha a propriedade privada ou os meios de produção. A atuação estatal era no sentido de não intervir nos assuntos de cunho socioeconômicos.

\subsection{A Constituição Mexicana de $1917^{14}$}

O que se verificou foi que era inconcebível uma atuação estatal no sentido de manter-se omissa em relação a uma série de direitos sociais que passaram a ser exigíveis no decorrer do século XX. As cartas políticas foram concebidas como receptáculos de uma ordem política liberal, cuja neutralidade econômica revelava uma opção liberal (TAVARES, p. 708, 2017).

A necessidade de fazermos um registro da Constituição mexicana de 1917 é que se caracterizou por ser uma mudança no cenário até então vigente um verdadeiro paradigma transformador, pois foi a partir desta Carta Política que uma série de direitos dito sociais foi primeiramente introduzida dentro de um sistema política. Isto em grande parte deveu-se as transformações políticas que se verificaram no decorrer dos séculos XVIII e XIX de caráter eminentemente liberal burguês em que a preocupação com os direitos sociais era inexistente.

Assim, este modelo estatal de cunho liberal, a partir da difusão do pensamento marxista passou a ser repensado, pois uma série de movimentos sociais passaram a ser verificados na Europa, fruto da consciência da classe proletária que deveria ser organizar e promover uma revolução. Portanto, esta é a primeira constituição do mundo a promover direitos sociais em favor das classes mais desprotegidas, no classe os trabalhadores e campesinos. Outro ponto que

\footnotetext{
${ }^{14}$ Muito embora se ressalte a importância da Constituição Alemão de 1919, em verdade, a primeira Carta Política paradigmática em relação aos direitos trabalhístas é a Constituição Mexicana de 1917, que introduziu o modelo de constitucionalismo social econômico, em que uma série de direitos sociais foram introduzidos.
} 
merece ser ressaltado foi a necessidade de se promover uma distribuição equitativa da riqueza ${ }^{15}$.

Assim, é inquestionável a relevância que teve a difusão do pensamento marxista na modificação das concepções de Estado verificadas pós 1917. A Constituição do México foi paradigmática, pois foi a primeira Carta Política a promover uma releitura do papel estatal, promovendo uma série de direitos sociais que tiveram um papel relevante e foram replicadas em outros textos constitucionais como, verbi gratia, na Constituição de Weimar de 1919 e no caso do Brasil na Constituição de $1934^{16}$.

\subsection{A relevância histórica da Revolução Russa de 1917}

Cabe ainda enfatizarmos a importância que a Revolução Russa de 1917 teve para a internalização dos direitos sociais, econômicos e culturais. Este movimento revolucionário foi profundamente influenciado pelo pensamento marxista do século XIX e caracterizou-se por ser uma ruptura com o modelo político vigente na Rússia. Contudo, deve-se enfatizar que a Rússia anterior a revolução era caracterizada por ser uma sociedade agrícola e que era governada ainda por um regime monarca absolutista, portanto, não havia uma classe econômica burguesa.

Assim, pode-se destacar que o processo revolucionário russo combateu ao Czarismo secular e absolutista. A insatisfação generalizada resultou no sentimento de libertação e ruptura do sistema administrativo vigente por meio de discursos, greves e atos violentos para a implantação do sistema socialista proletário. (PAULO, p. 64, 2017).

Portanto, mesmo não sendo um movimento da classe proletária em face da classe burguesa, não se deve excluir a importância que a Revolução Russa de 1917 caracterizou, pois uma série de direitos sociais foram instituídos, muito embora posteriormente se tenha verificado um desvirtuamento do pensamento marxista com a ascensão de Stálin ao poder. Não se deve menosprezar o papel que a revolução teve pós 1917.

\section{AS MUDANÇAS VERIFICADAS NO CONTEMPORANEIDADE}

\footnotetext{
${ }^{15}$ Não é objeto de análise deste texto a análise detalhada do texto constitucional mexicano de 1917, mas enfatizarmos que os arts. 27 e 28 elencavam uma série de direitos sociais, com o fito de promover a redução das desigualdades sociais, dentre os quais: disciplinava a propriedade privada, a fixação de medidas necessárias para promover o fracionamento dos latifúndios e a criação de novos centros de produção agrícola.

${ }^{16}$ Cabe aqui enfatizarmos que a Constituição do Brasil de 1934 surgiu em um contexto democrático muito peculiar, pois foi fruto da Revolução de 1930, que clamava por valores republicanos e mais democráticos, superando o aparato institucional e político criado pelas oligarquias brasileiras, o modelo constitucional anterior havia caducado, pois não valia aos valores consagrados com a vitória da revolução. (TAVARES, p. 722, 2017).
} 
Ao se analisar o desenvolvimento do capitalismo durante o final do século passado e do atual é indissociável o questionamento que se faz acerca do pensamento marxista, pois a revolução do proletariado tão difundida no pensamento marxista não se efetivou. Ao revés, o que se tem observado é que o capitalismo se desenvolveu de forma tal que a renda e distribuição da riqueza encontram-se concentradas de forma ainda maior.

As teorias desenvolvidas por Marx e Engels, em grande medida, como o desenvolvimento do comunismo e a consciência de classes não se efetivaram. No século XX, mudaram burguesia e proletariado. As relações de produção se revelaram mais elásticas do que Marx imaginava. A Consciência de classe não se desencadeou no sentido que Marx previra. Essas mudanças afetaram o cerne do marxismo. (KONDER, p. 60, 2010).

O desenvolvimento do capitalismo desencadeou uma mudança das relações não só de trabalho, mas também das relações culturais. O consumismo acarretou uma mudança significativa das relações sociais, pois o público consumidor é manipulado, e não atua como sujeito, não fazendo escolhas efetivamente livres. Em seus escritos Marx asseverou que ópio do povo era religião; já para pensadores marxistas do século XX como Habermas, Adorno, Fromm e Marcuse, o consumismo no Ocidente tinha se tornado o ópio das massas. (JEFFRIES, p. 319,2018$)^{17}$.

Assim, o pensamento marxista deveria ser repensado, pois com o triunfo do capitalismo muitas das teorias de Marx deveriam ser repensadas.

Outro ponto que também deve ser objeto de consideração diz respeito a mudança verificada na concepção do Estado como provedor dos direitos sociais. Verificou-se, contudo, que nas últimas décadas do século passado e início do século atual foi implantado, de forma sistemática, a política de retirada do Estado do domínio tanto econômico, quanto social como tentativa de se estancar as crises econômicas verificadas no mercado, essas políticas primavam por promover uma redução do papel social do Estado, principalmente em se tratando de promoção das políticas públicas, bem como de liquidar os déficits orçamentários acarretados por este Estado Social (CLARK, 2009, p.12).

Ou seja, anteriormente tínhamos um Estado provedor das principais políticas públicas,

\footnotetext{
${ }^{17}$ Embora não seja objeto deste trabalho a análise dos pensadores marxistas dos séculos XX e XXI cabe ressaltar a importância que a Escola de Frankfurt teve na reinterpretação do pensamento marxista. Esta escola era associada ao Instituto de Pesquisa Social da Universidade de Frankfurt e à medida em que evoluía, durante a década de 30 do século passado, tentava empreender uma análise neomarxista e tentava compreender porque a revolução marxista não se operara na Alemanha. Esta escola teve como expoentes Theodor Adorno, Max Horkheimer, Walter Benjamin, Erich Fromm, Herbert Marcuse, Jürgen Habermas, dentre outros.
} 
que intervinha de forma direta, para um Estado regulador na qual a entrega direta dos principais serviços públicos não é mais atribuição estatal e sim de terceiros. Neste último cenário cabe ao Estado uma atuação não de prestação direta e sim de fiscalização da atividade repassada a terceiros. Este processo culminou com uma nova concepção de Estado, de matriz neoliberal.

$\mathrm{Na}$ contemporaneidade, o neoliberalismo teve como principal base teórica às ideias da Escola Americana de Economia, lideradas por Milton Friedman ${ }^{18}$. Sobre as premissas de uma mínima ação do Estado na realidade socioeconômica foi construído o Consenso de Washington ${ }^{19}$. Em linhas gerais pode-se definir a política defendida por este consenso com um atuar mais destacado do mercado. Menos Estado, mais mercado.

As implicações da adoção da política neoliberal nos Estados acarretaram significativas mudanças nos textos constitucionais e de reformas administrativas de diversos países, a fim de amoldarem seus textos as novas exigências de uma atuação estatal menos provedora das políticas públicas e mais de regulação da atividade estatal ${ }^{20}$.

Assim, é neste contexto que o pensamento marxista deve ser inserido, pois houve uma modificação tanto do papel estatal, atualmente regulador; quanto da classe proletária. Muitas das ideias difundidas por Marx não se efetivaram, contudo, não se deve menosprezar a teoria marxista no contexto atual, pois a miséria gerada pela concentração de renda advinda do desenvolvimento do capitalismo aumentou. Críticas estas que foram feitas por Marx e que continuam atual, mesmo se desenvolvendo um estado provedor de direitos sociais, tal qual verificado, ainda assim, as desigualdades sociais estiveram presentes.

\footnotetext{
${ }^{18}$ Professor da Universidade de Chicago, ganhador do Nobel em Economia, vinculado a Escola Americana de Chicago, que desenvolveu as principais tese da política neoliberal.

${ }^{19}$ Entende-se por Consenso de Washington uma recomendação internacional elaborada em 1989, que visava a propalar a conduta econômica neoliberal com a intenção de combater as crises e misérias dos países subdesenvolvidos, sobretudo os da América Latina e se tornou a política oficial do Fundo Monetário Internacional. Sua elaboração ficou a cargo do economista norte-americano John Williamson do International Institute for Economy.

${ }^{20}$ A respeito do processo de modificação verificado em diversos textos constitucionais por conta da mudança de concepção estatal surgidas com o neoliberalismo destaca Sousa Santos "as implicações destas transformações para as políticas econômicas nacionais podem ser resumidas nas seguintes orientações ou exigências: as economias nacionais devem abrir-se ao mercado mundial e os preços domésticos devem tendencialmente adequar-se aos preços internacionais; deve ser dada prioridade à economia de exportação; as políticas monetárias e fiscais devem ser orientadas para a redução da inflação e da dívida pública e para a vigilância sobre a balança de pagamentos; os direitos de propriedade privada devem ser claros e invioláveis; o sector empresarial do Estado deve ser privatizado; a tomada de decisão privada, apoiada por preços estáveis, deve ditar os padrões nacionais de especialização; a mobilidade dos recursos, dos investimentos e dos lucros; a regulação estatal da economia deve ser mínima; deve reduzir-se o peso das políticas sociais no orçamento do Estado, reduzindo o montante das transferências sociais, eliminando a sua universalidade, e transformando-as em meras medidas compensatórias em relação aos estratos sociais inequivocamente vulnerabilizados pela atuação do mercado.” (SANTOS, 2005, p. 29-30)
} 


\section{CONCLUSÃO}

O artigo em tela se propôs a fazer uma análise de importância do pensamento marxista e de sua atualidade, pois mesmo não tendo se concretizado muitos das suas teses, como o fim do capitalismo. Não se deve rechaçar que muitas de suas ideias tiveram contribuição para modificação da concepção de Estado e das estruturas presentes na sociedade.

Por certo, passados duzentos anos de seu nascimento, não se deve olvidar que as contribuições, tanto filosóficas, quanto econômicas tiveram significativa importância dentro do desenvolvimento das relações sociais. O pensamento marxista desencadeou uma série de reflexões a acarretou significativas mudanças na concepção do Estado.

Marx fundou grande parte de seu pensamento na conscientização da classe dominada, no caso da classe proletária, de que os interesses muitas vezes defendidos pelo Estado não representam os anseios da coletividade, pois este dito Estado se presta a defesa e promoção da classe dominante. A institucionalização das normas e das regras sociais é fruto da intervenção humana na realidade social e estão sempre ligadas a estrutura de classes presentes na sociedade. Neste cenário o direito surge como instituição social responsável por manter, estabelecer e propagar a nova ordem social da classe dominante.

Para Marx, ao longo da história e dos diferentes modos de produção, constituíram-se, em regra, duas grandes classes: uma dominante e outra dominada; como os donos de escravos, servos e senhores feudais e, finalmente, a burguesia e o proletariado. A ideologia, nas sociedades de classes como a capitalista, vai representar o modelo idealizado de Estado, bem como o estabelecimento das regras de funcionamento desse Estado. Existem as infraestruturas que seriam as forças produtivas e as relações sociais de produção; e as superestruturas vinculadas as relações ideológicas, políticas e jurídicas. Dentro do conceito de superestruturas Marx vai trabalhar os tipos de consciência coletiva existentes nas sociedades modernas. É importante frisar que dentro da sociedade as ideias de uma determinada classe passam a ter prevalência dentro da sociedade (no caso a ideologia da classe dominante), e passam a ser assimiladas como válidas pelos membros da sociedade como um todo. Contudo, ressalta Marx, que cabe ao grupo dominado ter consciência desta dominação e passar a combatê-la.

Neste contexto o direito não será justo para todas os grupos sociais, pois se prestará para manter a ordem do Estado ( $O$ Estado é o Estado da classe dominante, as ideias da classe 
dominante são as ideias dominantes de cada época), pois a ideologia dominante não reflete a homogeneidade da sociedade. Marx observa que a ordem jurídica prega que os cidadãos são iguais perante a lei e que o contrato social beneficia a todos, contudo, trata-se de uma ilusão, pois a igualdade formal pregada pelo Estado beneficia apenas uma parcela da sociedade.

Este pensamento marxista foi fundamental para que a partir do século XX muitas constituições passassem a prevê uma série de direitos sociais, como forma de mitigar os efeitos do desenvolvimento do capitalismo, pois as desigualdades sociais desencadeados pela exploração dos detentores dos meios de produção em relação aqueles que detinham a força do trabalho desencadearam a alienação do trabalhador. Portanto, malgrado as críticas que se fazem ao marxismo, não se deve olvidar da sua relevância para a atualidade, mormente se analisarmos que muitos dos direitos sociais só foram conquistados a partir de uma mudança de concepção do Estado desencadeada por revoluções que ocorreram a partir de seu pensamento.

Assim, a máxima que encerra o Manifesto Comunista de 1848 da necessidade de união da classe dominada para a consolidação de seus direitos continua atual.

\section{REFERÊNCIAS}

ALARCÓN, Pietro Lora. Teoria Geral do Direito Constitucional: a contribuição do marxismo. Revista brasileira de Direito Constitucional. No 6, jul/dez, 2005.

ALTHUSSER, Louis. Por Marx. Campinas, SP: Editora Unicamp, 2015.

Hegel. Lisboa: Editora Estampa, 1981.

- Transformações da filosofia seguido de Marx e Lenine perante

ARON, Raymund. O marxismo de Marx. São Paulo: Arx, 2005.

BOBBIO, Norberto. Escritos sobre Marx: dialética, Estado, sociedade civil. São Paulo: Martins Fontes, 2018.

BORON, Atilio A. Filosofia política e crítica da sociedade burguesa: O legado teórico de Karl Marx. DCP-FFLCH, Departamento de Ciências Políticas, Faculdade de Filosofia Letras e Ciências Humanas, USP, Universidade de São Paulo, 2006.

CLARK, Giovani. O neoliberalismo de regulação como intervenção do Estado. Revista Lusíada. Economia \&mercado, $n^{\circ}$ 9. p. 11-30, 2009.

FREITAS, Amílcar Cardoso Vilaça de. O direito moderno sob a ótica dos clássicos da sociologia: análises e questionamentos. Revista Caderno CRH, Salvador, v. 26, n. 69, p. 639- 
653, set/dez, 2013.

GRUPPI, Luciano. Tudo começou com Maquiavel. 14ª edição. Porto Alegre: L\&PM, 1996.

JEFFRIES, Stuart. Grande hotel abismo: a Escola de Frankfurt e seus personagens. São Paulo: Companhia das Letras, 2018.

KONDER, Leandro. O que é dialética. $28^{\mathrm{a}}$ edição. São Paulo: Brasiliense, 2008. . Em torno de Marx. São Paulo: Boitempo, 2010.

LOWY, Michael. Ideologias e ciência social: elementos para uma análise marxista. $13^{a}$ edição. São Paulo: Cortez, 1999.

LUKÁCS, Georg. História e consciência de classe: estudos sobre a dialética marxista. São Paulo: Martins Fontes, 2003.

Marx, Karl. Manifesto Comunista. São Paulo: Boitempo, 2010.

PAULO, Guilherme Barbon. A Revolução russa de 1917 e os direitos fundamentais de segunda dimensão. Revista do departamento de história e do programa de pós graduação em história do Brasil da UFPI. Teresinha, vol. 6, nº 1, jan/jun. 2017.

POPPER, Karl Raimund. A sociedade aberta e seus inimigos. Vol. 2. Belo Horizonte: Editora Itatiaia, 1987.

QUINTANEIRO, Tânia. Um toque de clássicos: Marx, Durkheim e Weber. $2^{\mathrm{a}}$ edição. Belo Horizonte: Editora UFMG, 2009.

SANTOS, Boaventura de Sousa. A globalização e as ciências sociais. $3^{\text {a }}$ edição. São Paulo: Cortez, 2005.

SILVA, Maria Letícia Barbosa Miranda da. Materialismo histórico e sua influência na teoria histórico cultural. Revista Tramas para reencantar o mundo. n. 1, maio. 2015.

TAVARES, André Ramos. Influência de 1917 na doutrina e nas Constituições econômicas brasileiras. Universidade Nacional Autônoma de México. Secretaria de Cultura - Instituto nacional de estudos históricos de las revoluciones de México. 2017.

WINDHOLZ, Eric. Conceituando regulação social e econômica: implicações para agentes reguladores e para atividade regulatória atual. Revista de Direito Administrativo, Rio de Janeiro, v. 264, p. 13-56, 2013 
Quaestio Iuris

Trabalho recebido em 25 de maio de 2020

Aceito em 29 de outubro de 2020 